\title{
The Effect of Nutritional Education with Leaflet and Diet Application on Nutritional Status Changes in Obese College Students
}

\author{
Diah Puspa ${ }^{1}$, Dian Handayani $^{2}$, Inggita Kusumastuty $^{\circledR}$
}

${ }^{1}$ Master Program in Biomedical Science, Faculty of Medicine, Universitas Udayana, Bali, Indonesia

Article Info

Article History:

Submitted December 2020

Accepted June 2021

Published July 2021

Keywords:

Leaflet media, My weight loss

diet application, body mass

index, body fat percentage

DOI

https://doi.org/10.15294/ ujph.v10i2.43150

\begin{abstract}
Obesity is excessive body fat condition due to differences in energy consumption and expenditure. In Indonesia, the prevalence of obese women $>18$ years old is $32.9 \%$. Interventions are performed with control eating and increased physical activity through an educational approach. A Leaflet is a print media containing some information, while my weight loss diet application is used by people that want to lose weight. Therefore, this study aims to determine the effect of nutritional education with leaflet and my weight loss diet application on nutritional status changes in obesity. True experimental design was used with pre-post test on female students divided into two groups in Universitas Brawijaya $(n=44)$ and selected by purposive sampling. Also, Independent-Samples TTest and Mann Whitney analysis were conducted. The results showed a body mass index decrease in both media and no significant change related to BMI $(p=0.733)$. However, the decrease was more shown on the leaflet, where the body fat percentage had a significant change $(p=0.000)$. Hence, intervention using the leaflet is more effective on nutritional status changes related with BMI and body fat percentage in obese students.
\end{abstract}

\section{INTRODUCTION}

Obesity is a physical condition where there is accumulation of fat in the body as a result of excessive energy consumption compared to the energy expenditure, thus it resulted in weight gain. This is caused by an increase in the consumption of foods with high levels of sugar and fat followed by a lack of physical activity which can cause risk of health problems such as type 2 diabetes mellitus, cardiovascular disease, hypertension, stroke, and cancer (Jung \& Choi, 2014).

In 2015 , as many as 1.5 billion adults were overweight with more than 200 million being obese in women. Basic Health Research 2013 by Indonesian Ministry of Health recorded the prevalence of obesity in women $>18$ years old was $32.9 \%$, which increased from $15.5 \%$ in 2010 . Obesity occurs mostly in adult women due to changes in body composition, unhealthy eating behavior which is balanced with low physical activity. Most cases happen in college students that are busy with their schedule and activity affecting on unhealthy lifestyle (Todd et al., 2015; Tauqeer et al., 2018).

Intervention is needed in reducing the number of obesity incidents by controlling eating and increasing physical activity through an educational approach. Nutrition education is an effort to promote health related to healthy eating habits. Education can be done through various

\footnotetext{
Correspondence Address:

Department of Nutrition Science, Faculty of Medicine, Universitas Brawijaya, Ma-

lang, Indonesia

E-mail: diahpuspa977@gmail.com 
media such as printed media, electronic media, and board media. Education with the help of the media will make it easier for people to receive and understand educational materials (Fitriani, 2011). Nutrition education using printed leaflets is known to increase knowledge and influence food consumption. Knowledge of the nutritional value of food was believed to change dietary behaviors because nutritional knowledge would encourage people to consume a healthier diet. However, extensive studies have shown that educating people about the health benefits of nutritious food is not sufficient to effect necessary dietary changes. Mediator variables which can be personal, physical, environmental, behavioral, or familial are necessary in the formation of dietary behaviors. Likewise, education through applications that are easily accessed anytime and anywhere to be able to access information (Fitriani, 2011). Education using leaflet and diet application shows an increase in knowledge related to wight loss diet in obese students (Hapsari, 2018). This study will examine the effect of giving nutrition education with leaflet media and the application of my weight loss diet on changes of nutritional status in obese female students.

\section{METHODS}

This study used a true experimental research design with pre and posttest group design in two groups, namely the leaflet media group and the application of my weight loss diet group. In posttest, it is for looking changes in nutritional status carried out 1 month after giving education. This research has received a letter of ethical eligibility from the health research ethics commission of the medical faculty of Universitas Brawijaya with No. 324A / EC / KEPK - S1- GZ / 09/2017.

The study population was obese female students at Universitas Brawijaya. The sample was selected by using purposive sampling technique in determining the respondents. Total number of respondents was 44 people divided into two groups. Those were 22 people in the leaflet media group and 22 people in the "My Weight Loss Diet Application" group. The criteria for respondents in both groups are female students 19 22 years old, body mass index (BMI) $\geq 25 \mathrm{~kg} /$ $\mathrm{m}^{2}$, not on a diet, not taking weight loss drugs, and having an android-based smartphone in the application group.

The dependent variable was the changes of nutritional status. Then there is a mediator variable it was physical activity. Meanwhile, the independent variable in this study was the provision of education with different media in 2 groups: leaflet media and the application of my weight loss diet. This research was conducted in Universitas Brawijaya with respondents from all faculties in Universitas Brawijaya. It had started from July 2017 to January 2018. The instruments used in this study were bodyweight scales, microtoise, bioimpedance analysis (BIA), leaflet media, android-based smartphones with the " $M y$ Weight Loss Diet Application", questionnaire for respondent characteristics, IPAQ physical activity questionnaire, and a laptop to process data using computer program.

Nutritional status can be seen from the body mass index and percent fat of the respondent by measuring for 1 month done once a week to determine changes in nutritional status in respondents (Handayani et al., 2015). In addition of nutritional status, the respondent's measurement of physical activity for a week was also carried out by filling out the IPAQ physical activity questionnaire which consists of work-related activities, homework activities, and leisure activities and sports which are carried out once a week. The answers to the questionnaires will be numbered and categorized based on IPAQ (IPAQ, 2005).

The data collection begun with a physical activity questionnaire validation test, then looked for respondents who matched the inclusion criteria and provided informed consent as a statement of willingness to become respondents. During the research implementation, the measurement of nutritional status related to BMI and percent of body fat as well as the physical activity of the respondents and divided the respondents into two groups followed by giving nutrition education using leaflet media and the application of my weight loss diet. The study was conducted for a month and once a week, nutritional status and physical activity were measured. Furthermore, there were analyzing data before and after education, testing differences in nutritional status changes in the two groups and examining the relationship between changes in physical activity and changes in nutritional status. The data analysis started with the normality test of Saphiro Wilk because the respondents are $<50$ people and tested to determine differences in nutritional status and physical activity before and after between the two groups using the Independent Sample Test. Meanwhile, the test for differences on changes in nutritional status between the two groups used the Mann Whitney test with $\mathrm{p}$ value $<0.05$. 
Table 1. General terms of respondents

\begin{tabular}{llll}
\hline \multirow{2}{*}{ Category } & $\begin{array}{l}\text { Leaflet } \\
(\mathrm{n}=22)\end{array}$ & $\begin{array}{l}\text { My Weight Loss Diet } \\
(\mathrm{n}=22)\end{array}$ & Total \\
\cline { 2 - 4 }$(\%)$ & $(\%)$ & $\mathrm{N}(\%)$ \\
\hline$\underline{\text { Age }}$ & & $0(0 \%)$ & $3(6.8 \%)$ \\
19 years old & $3(6.8 \%)$ & $3(6.8 \%)$ & $10(22.7 \%)$ \\
20 years old & $7(15.9 \%)$ & $15(34.1 \%)$ & $24(54.5 \%)$ \\
21 years old & $9(20.4 \%)$ & $4(9.1 \%)$ & $7(15.9 \%)$ \\
22 years old & $3(6.8 \%)$ & & \\
Major & & $3(6.8 \%)$ & $9(20.5 \%)$ \\
Medical & $6(13.7 \%)$ & $19(43.2 \%)$ & $35(79.5 \%)$ \\
Non Medical & $16(36.3 \%)$ & & $21(47.7 \%)$ \\
BMI (kg/m $\left.{ }^{2}\right)$ & & $13(29.5 \%)$ & $23(52.3 \%)$ \\
Obesity 1 & $8(18.2 \%)$ & $9(20.5 \%)$ & \\
Obesity 2 & $14(31.8 \%)$ & &
\end{tabular}

\section{RESULTS AND DISCUSSION}

\section{Characteristics of Respondents}

Based on Table 1, total respondents who participated in this research were 22 people. The respondents came from some faculties in Universitas Brawijaya. It can be seen that most of the respondents in the two groups are 21 years old with 9 people $(20.4 \%)$ in the leaflet media group and 15 people (34.1\%) in the "My Weight Loss Diet Application" group.

In the field of study, the respondents in the leaflet media group were 16 people $(36.3 \%)$ and the "My Weight Loss Diet Application" group 19 people $(43.2 \%)$ are non-health fields. It was only 9 respondents who are medical students. Judging from the nutritional status, the respondents in the leaflet media group are obesity level 2 around 14 people $(31.8 \%)$ and the application group are 13 people (29.5\%) with obesity level 1.

Overall, the age of the respondents in the study was adjusted to the inclusion criteria, which was an age range of 19-22 years old. Most of the respondents were 21 years old in both groups. The incidence of obesity mostly occurs during adulthood where there are changes in body composition, selection and eating behavior with sedentary activities and psychological changes (Mahan et al., 2012; Patton et al., 2010).

In this study, most of the respondents study in non-health fields, which consist of several faculties in Universitas Brawijaya. The level of education is related to a person's ability to receive information which can increase knowledge and affect a person's attitude and behavior. Sufficient nutrition information can increase knowledge related to eating habits and physical activity that can affect nutritional status (Dewi, 2015).

Most of the respondents in this study had nutritional status level 1 and level 2. Nutritional status is a person's condition influenced by the consumption and absorption of nutrients in food. Nutritional status can be affected by food consumption and physical activity. The balance between nutritional needs and intake will achieve optimal nutritional status (Grygiel-Górniak et al., 2016). In determining nutritional status, parameters include body mass index and percent of body fat. A person can be said to be obese if he has a BMI $>25 \mathrm{~kg} / \mathrm{m}^{2}$ and percent body fat is more than $30 \%$.

\section{Nutritional Status before and after Education with Leaflet and My Weight Loss Diet Appli- cation}

Nutritional status of respondents before providing education through both media shows that there is no difference in BMI $p=0.256$ and body fat percentage $p=0.892$ of respondents before giving education with two media. However, there is a difference in physical activity $\mathrm{p}=0.009$ on both media.

The nutritional status based on BMI is 14 respondents $(31.8 \%)$ in the leaflet media group with obesity level 2 while the "My Weight Loss Diet Application" group is approximately 13 respondents $(29.5 \%)$ with obesity level 1 . In the body fat percentage, all respondents in both groups have more than $30 \%$ percent fat whereas normal value of fat percentage is $20 \%-25 \%$. Thus, they are 
Table 2. Nutritional Status before Education with Leaflet and My Weight Loss Diet Application

\begin{tabular}{llll}
\hline Group & & & \\
\hline & Leaflet & My Weight Loss Diet & p-Value \\
\hline BMI $\left(\mathrm{kg} / \mathrm{m}^{2}\right)$ & $31.74 .33^{*}$ & 29 & 0.256 \\
& & $(26.7-32)^{* * *}$ & \\
Body Fat Percentage & 37.63 .15 & 37.53 .45 & 0.892 \\
Physical Activity & 633 & 967 & 0.009 \\
& $(268.8-1146)^{* *}$ & $(445-5526)^{* * * *}$ & \\
\hline
\end{tabular}

Information:

There is a significant difference if the $\mathrm{p}$ value $<0,05$, Independent Samples Test

* Mean SD

** Median (Perc $25-$ Perc 75)

$* * *$ Transform BMI $=1 /$ Pre BMI

**** Transform physical activity $=\log 10$ (Pre AF)

classified as obese. The physical activity of respondents is 11 respondents $(25 \%)$ with moderate level in the leaflet media group. While the " $M y$ Weight Loss Diet Application" group there is 8 respondents $(18.2 \%)$ with light and heavy levels.

Meanwhile in table 3 shows there is no difference in BMI $p=0.26$, body fat percentage $p=0.274$, and physical activity $p=0.069$ after providing education on both media. BMI shows that 14 respondents $(31.8 \%)$ in the leaflet media group as obesity level 2, while the "My Weight Loss Diet Application" group is around 13 respondents (29.5\%) obesity level 1 . In the body fat percentage, all respondents in both groups had more than $30 \%$ percent fat. Hence, they are classified as obese. There are 17 respondents (38.6\%) with moderate physical activity in the leaflet group and 9 respondents (20.5\%) in the "My Weight Loss Diet Application" group with moderate physical activity.

The results of the analysis of nutritional status based on BMI and physical activity before and after giving education in the two groups showed that most of the nutritional status of respon-

dents had obesity level 1 with range of BMI 25-29 $\mathrm{kg} / \mathrm{m}^{2}$ and obesity level 2 with $\mathrm{BMI} \geq 30 \mathrm{~kg} / \mathrm{m}^{2}$. The results showed that there is no difference in BMI with $p=0.256$ and there is no difference in the percentage of fat with $p$ value $=0.892$ before education. Moreover, after giving education there is no difference in BMI with p value $=0.26$ and fat percent with $p=0.274$. The increase in BMI and percentage of fat in the body is due to changes in unhealthy lifestyles such as consumption of high-fat foods, lack of consumption of vegetables and fruits and low physical activity (Jaminah \& Mahmudiono, 2018). Physical activity before education is different in the two media with $p=0.009$ and no difference after education with $\mathrm{p}=0.069$.

Physical activity is related to a healthy quality of life. Physical activity indirectly affects the Body Mass Index (BMI), where low physical activity will affect body changes that becomes accumulation of fat in the stomach in adult women. This risk can be reduced by increasing physical activity which can change the total body fat or energy consumption (Hastuti, 2013). The seden-

Table 3. Nutritional Status after Education with Leaflet and My Weight Loss Diet Application

\begin{tabular}{llll}
\hline Group & & & \\
\hline & $\begin{array}{l}\text { Leaflet } \\
\text { (Mean SD) }\end{array}$ & $\begin{array}{l}\text { My Weight Loss Diet } \\
(\text { Mean SD) }\end{array}$ & p-Value \\
\hline BMI $\left(\mathrm{kg} / \mathrm{m}^{2}\right)$ & $31.64 .36^{*}$ & $\begin{array}{l}28.8 \\
(26.6-31.8)^{* *}\end{array}$ & 0.26 \\
Body Fat Percentage & 37.73 .03 & 38.93 .88 & 0.274 \\
Physical Activity & 1100586 & $\begin{array}{l}923.5 \\
(436-2830)^{* * *}\end{array}$ & 0.069 \\
\hline
\end{tabular}

Information:

There is a significant difference if the $\mathrm{p}$ value $<0,05$, Independent Samples Test

* Mean SD

** Median (Percentil $25-$ Percentil 75), Transform BMI $=1 /$ Post BMI

***Transform Physical activity $=$ Log10 (Post AF) 
Table 4. Changes of Nutritional Status between Leaflet and My Weight Loss Diet Application

\begin{tabular}{|c|c|c|c|}
\hline & Group & $\begin{array}{l}\text { Median } \\
\text { (Perc 25-Perc 75) }\end{array}$ & $\begin{array}{l}\mathrm{p}- \\
\text { Value }\end{array}$ \\
\hline \multirow{2}{*}{ BMI $\left(\mathrm{kg} / \mathrm{m}^{2}\right)$} & Leaflet & $-0.087(-0.23-0.05)$ & \multirow{2}{*}{0.733} \\
\hline & My Weight Loss Diet & $-0.075(-0.23-0.068)$ & \\
\hline \multirow{2}{*}{ Body Fat Percentage } & Leaflet & $-0.625(-0.36-0.18)$ & \multirow{2}{*}{0.000} \\
\hline & My Weight Loss Diet & $1.42(0.16-2.49)$ & \\
\hline \multirow{2}{*}{ Physical Activity } & Leaflet & $168(-165-715)$ & \multirow{2}{*}{0.003} \\
\hline & My Weight Loss Diet & $-158(-2734-61.59)$ & \\
\hline
\end{tabular}

tary nature of a lifestyle is a factor in the occurrence of obesity, rarely doing sports and doing more activities that require less energy (Ostovan et al., 2013).

\section{Analysis of Changes in Nutritional Status between Leaflet and My Weight Loss Diet Ap- plication}

Changes in nutritional status between the two groups can be presented in the form of median, 25th percentile, and 75th percentile. Based on Table 5 , it shows that there is no significant difference in changes related to BMI with $p$ value $=0.733$ in both media. However, there are differences in changes in the body fat percentage with $p$ value $=0.000$ and physical activity with $p$ value $=0.003$ in both media.

The results of the analysis of the difference changes in nutritional status based on BMI between two groups showed that there is no significant difference in changes with $p$ value $=0.773$. The study, which was conducted for a month, there was a decrease in the BMI value of respondents in both groups seen from the median value of BMI in the leaflet group that was a decrease around -0.087, while the "My Weight Loss Diet Application" group had a median value -0.075 which meant a decrease in BMI.

Hence, a decrease of BMI in leaflet group was higher than the application group. Based on the nutritional status category, the leaflet group was not different after education, those were obesity level 1 and obesity level 2, while in the "My Weight Loss Diet Application" group there was a difference after education, those were overweight, obesity 1 , and obesity 2 .

The difference in BMI changes was not significant in the two groups because respondents did not monitor themselves properly even though they knew the food consumed would affect on body weight. The results of this study are similar with Lanita's study (2015) related to the effect of health education on obesity via SMS and booklets which shows a decrease in the mean of BMI after the intervention, although the results of comparisons between media are not significant. In addition, the difference in insignificant changes occurred because implementing a diet requires motivation and dietary adherence from the respondents themselves (Lanita et al., 2015).

The percent of respondents' fat indicated that there were significant differences between the leaflet group and the "My Weight Loss Diet Application" group with $\mathrm{p}$ value $=0.000$. The difference of changes in the body fat percentage can be seen from the median value in the leaflet media group was -0.625 , which meant there was a decrease in fat percent, while the "My Weight Loss Diet Application" group had a median value $=1.42$ which meant an increase in fat percent. Monitoring was carried out for a month. In the leaflet group, aproximately 14 respondents experienced a decrease in body fat percent and around 4 respondents in the "My Weight Loss Diet Application" group experienced a decrease in body fat percent. However, the average value of the percent fat in both groups is still more than $30 \%$ which is classified as obese. This happened because the respondent before the monitoring had consumed food and drinks every week which could affect the nutritional status. In addition, dehydration or abnormal water levels in the body can affect the results of calculating the percentage of body fat using BIA (Heriyanto, 2012).

Apart from the respondent's food intake, physical activity also affects changes in nutritional status (Willis et al., 2012). In this study, there was an increase in the physical activity in the leaflet group and a decrease in the level of physical activity in the "My Weight Loss Diet Application" group. Most of the physical activities carried out by respondents belong to the category of light and moderate physical activity. In the leaflet media group, most of the physical activity performed increased in the moderate category, but there was a decrease in physical activity, initially there were 
some respondents who had a heavy level of physical activity become nothing. Meanwhile, in the "My Weight Loss Diet Application" group, most of the respondents had moderate physical activity and there was a decrease in the proportion of respondents who had heavy physical activity (Hastuti, 2013). This happened because the activities carried out by respondents during one month of monitoring have different physical activities each week thus it is possible to have differences in physical activity implemented by respondents. It is possible that light and moderate physical activity does not require a lot of energy so that the energy that is not used for physical activity will form fat which can increase the percentage of fat in the body and accumulate to body weight which can affect nutritional status.

In this study, there is no in-depth analysis carried out related to understanding of the respondents on educational material in the program to improve nutritional status. Respondents only adhere to the recommended energy levels or are still within tolerance limits, but they do not try to reduce their food consumption which can affect respondents' adherence to the recommended diet changes in nutritional status by researchers. Prastika's research (2018) states that there was no difference in dietary adherence before and after education using leaflet media. This was because respondents did not apply the education that had been given and the desire to adhere to the recommended diet was still classified as low. However, there were differences in dietary adherence to respondents before and after education through the "My Weight Loss Diet Application" (Prastika, 2018).

The existence of dietary adherence to the "My Weight Loss Diet Application" can be caused by the advantages of the application media including easy application, can be carried everywhere, and accessed anytime and the food ingredients provided are quite complete. There was no significant difference in BMI changes, even though the respondents had good dietary adherence to the "My Weight Loss Diet Application" because the observation time was only a month. In healthy weight loss in obese people, it takes a period about 6 months with an average weight loss $10 \%$. In addition, the measurement of BMI is by dividing the weight and height (Mahan et al, 2012). In this study, there was a slight decrease in body weight in the respondents, so that these results did not affect the changes in BMI among respondents.

\section{CONCLUSION}

In this study, it showed that there was no difference in BMI and body fat percentage before giving education between both media. Furthermore, there was no difference in BMI and body fat percentage after giving education between both media. The results showed a decrease of BMI in both media but there was no significant change related to BMI where the decrease of BMI was more shown on leaflet media and there was a significant change in body fat percentage in the leaflet media.

\section{ACKNOWLEDGEMENT}

This article was presented in the $1^{\text {st }}$ International Nursing and Health Science Symposium (INHSS) "Adapting to New Habits: Strengthening Interprofessional Collaboration and Embracing Innovative Measures to Improve Quality of Healthcare Service" on 13-15 November 2020 organized by School of Nursing and Nutrition Department, Faculty of Medicine, Universitas Brawijaya, Malang Indonesia.

\section{REFERENCES}

Chen, Y., et al. 2020. The Promotion of Eating Behaviour Change through Digital Interventions. Int. J. Environmental Research and Public Health, 17 (20): 1-19. https://doi.o rg/10.3390/ijerph17207488

Dewi, N.A.A. 2015. The Influence of Health Education about Clean and Healthy Living Behavior with The Lecture Method on Knowledge and Attitudes in The Orphanage Children of Muhammadiyah Surakarta. Manuscript Publication. Surakarta: Muhammadiyah Surakarta University. http://eprints. ums.ac.id/40979/4/NASKAH\%20PUBLIKASI.pdf

Fitriani, S. 2011. Health Promotion, 1st Edition. Yogyakarta: Graha Science, p 176-180.

Grygiel-Górniak, B., Tomczak, A., Krulikowska, N., Przysławski, J., Seraszek-Jaros, A. \& Kaczmarek, E. 2016. Physical Activity, Nutritional Status, and Dietary Habits of Students of a Medical University. Sport Sciences for Health, 12 (2): 261-267. https:// doi.org/10.1007/s11332-016-0285-X

Handayani, D., Anggraeny, O., Dini, C.Y., Kurniasari, F.N., Kusumastuty, I., Tritisari, K.P. et al. 2015. Nutrition Care Process (NCP), First Edition. Yogyakarta: Graha Science, p 17-28.

Hapsari, U.A. 2018. Analysis of Differences in Knowledge Levels of Weight Loss Diets in Obesity Students Educated with Leaflet and the My Weight Loss Diet Application. Master Thesis. Malang: Department of Nutrition Science 
of Universitas Brawijaya. http://repository.ub.ac.id/id/eprint/167250

Hastuti, J. 2013. Anthropometry and Body Composition of Indonesian Adults: An Evaluation of Body Image, Eating Behaviours, and Physical Activity. Master Thesis. Australia: Faculty of Health Queensland, University of Technology. https:// eprints.qut.edu. $\mathrm{au} / 61740 /$

Heriyanto, M.H. 2012. Relationship of Nutrition Intake and Other Factors With Percent of Body Fat in Nutrition and Communication Science Student of Indonesia University Class of 2009. Master Thesis. Depok: Nutrition Study Program of University of Indonesia. http://lib.ui.ac.id/file?fil e=digital $/ 20319756$

IPAQ Research Commitee. 2005. Guidelines for Data Processing and Analysis of The International Physical Activity Questionnaire (Ipaq) Short and Long Forms. Internet. Cited 3 June 2017]. Available from: http://www.ipaq.k i.se.

Jaminah \& Mahmudiono, T. 2018. Relationship of Knowledge, Physical Activity with BMI of Female Employees in The Nutrition Installation of Dr. Soetomo Hospital. Jurnal Berkala Epidemiologi, 6 (1): 13-24. http:// dx.doi.org/10.20473/jbe.V6I12018.9-17

Jung, U. \& Choi, M. 2014. Obesity and Its Metabolic Complications: The Role of Adipokines and the Relationship between Obesity, Inflammation, Insulin Resistance, Dyslipidemia and Nonalcoholic Fatty Liver Disease. International Journal of $\mathrm{Mo}$ lecular Science, 15: 6184-6223. https://doi. org/10.3390/ijms15046184

Lanita, U., Sudargo, T. \& Huriyati, E. 2015. Effect of Health Education through Short Message Service (Sms) and Booklet about Obesity in Adolescents with Overweight and Obesity. Indonesian Journal of Clinical Nutrition, 12 (1): 36-44. https://doi. org/10.22146/ijcn.22920

Mahan, L., Stump, S. \& Raymond, J. 2012. Krause's Food and The Nutrition Care Process, $13^{\text {th }}$. United States of America: Elsevier, $\mathrm{p}$ 462-486.

Ostovan et al. 2013. The Impact of Education on Weight Loss in Overweight and Obese. International Cardiovascular Research Journal, 7 (3): 79-82. https://www.ncbi.nlm.nih. gov/pmc/articles/PMC3987437/

Patton, G.C., Coffey, C., Carlin, J.B., Sawyer, S.M., Williams, J., Olsson, C.A. \& Wake, M. 2010. Overweight and Obesity between Adolescent and Young Adulthood: a 10year Prospective Cohort Study. Journal of Adolescent Health, 48 (3): 275-280. https:// doi.org/10.1016/j.jadohealth.2010.06.019

Prastika, E.D. 2018. Analysis of Differences in Adherence to Diet on Obese Female Students Educated by Using Leaflet Media and The Application of My Weight Loss Diet. Thesis. Malang: Department of Nutrition Science of Universitas Brawijaya. http://repository.ub.ac. id/id/eprint/167241

Tauqeer, Z., Gomez, G. \& Stanford, F.C. 2018. Obesity in Women: Insights for the Clinician. Journal of Women's Health, 27 (4): 444-457. https://dx.doi. org/10.1089\%2Fjwh.2016.6196

Todd, A., Street, S., Ziviani, J., Byrne, N. \& Hills, A. 2015. Overweight and Obese Adolescent Girls: The Importance of Promoting Sensible Eating and Activity Behaviors from The Start of The Adolescent Period. International Journal of Environ. Research and Public Health, 12 (2): 2306-2309. https:// pubmed.ncbi.nlm.nih.gov/25690003/

Willis et al. 2012. Effects of Aerobis and/or Resistance Training on Body Mass and Fat Mass in Overweight or Obese Adults. Journal Applied Physiology, 113 (12): 1831-1837. https://www.ncbi.nlm.nih.gov/pmc/ articles/PMC3544497/ 